\title{
Intercultural Polylogues in Philosophy ${ }^{1}$
}

\author{
FRANZ M. WIMMER, VIENNA
}

1.

Since this is a conference of philosophers about philosophy and matters relevant to philosophy, I shall not talk about intercultural dialogues in general, nor will I speak about dialogues in the fields of religion or culture (fields which have to be distinguished, by the way), dialogues between politicians, etc. My statement will try to concentrate on intercultural dialogues in philosophy. This means, according to my understanding of "philosophy", that I have in mind essentially dialogues on ontological, on epistemological, or on normative questions.

\section{2.}

I propose not to talk about "dialogues" but about polylogues, considering that any question discussed by philosophers coming from different cultural backgrounds and traditions, ought to be argumented by the conceptual means and from the viewpoints of many, virtually from the viewpoints of all relevant philosophical traditions. The simple reason for the term "polylogue" lies in the fact that (a) the association with "dialogue" very often seems to be that there be (only) two parties involved - though the Greek "diá" simply means "between" or "inter" and does not imply any number and that (b) there are conceptual and methodological differences between dialogues where only two parties are involved compared to others where more than two are. Furthermore - which I only can state here, not exposing it - it is a fact that in most cases where there are cultural differences, rele-

\footnotetext{
${ }^{1}$ Statement to Panel "Intercultural Dialogue", $29^{\text {th }}$ Wittgenstein-Conference of the ALWS Kirchberg am Wechsel, August $11^{\text {th }}$ 2006. Other statements, in the order of contribution, have been given by: Mohammed Shomali (Qom, Iran), Patrick Riordan SJ (London, UK), and Eveline Goodman-Thau (Jerusalem, Israel)
} 
vant to philosophy, there will be more than two cultural traditions concerned.

\section{3.}

Now let me formulate my first question: What could be expected to be the subjects and the purposes of intercultural polylogues in philosophy?

I should like to answer this question in three steps: a) In many cases, mutual interest between philosophers who come from different cultural backgrounds, shall lead them to explaining to each other the different concepts and theories, and the meaning of what had been said in the teachings and texts of one's tradition. Without going into more details, I consider this process to be the aim of "comparative philosophy" with the purpose of understanding culturally different philosophy. As such, it is not yet what intercultural philosophical polylogues should aim at. b) In my opinion, the issue of intercultural dialogues or polylogues in philosophy is not only mutual understanding. It rather is mutual criticism, mutual enlightening, by activating all the different traditions of thought with their respective concepts and insights, their methods of argumentation, etc. c) So what would be the issues concerned? Theoretically, every philosophical question or concept or theory can be the subject of intercultural polylogues - and I seriously propose to consider non-occidental philosophical concepts and theories in whatever issue is concerned in philosophical discourse.

Practically, however, such subjects will be discussed in an intercultural orientation which is controversial from the point of view of the leading traditions of culturally different groups. Another example may show that there are various theoretical procedures to be expected.

If the universal validity of (some) ideas of human rights is criticised by the argument that they were of "western origin", we have to be aware that there are at least three levels of argumentation:

- Firstly, there is the question whether this is historically correct - and the argument can be doubted in that respect, at least partially. Such discussion on historical evidences, on possible contributions or influences will not de- 
cide the question, but will help to differentiate and to formulate the problem more clearly.

- Secondly, the general point that would have to be discussed is whether any idea could be universally valid if it originated from only one cultural tradition. The answer to be expected from philosophers of whatever cultural tradition, will be "yes", except for those who deny universal validity with regard to any issue.

- Thirdly, the argument might mean that the understanding of what "human being" means, differs between Western (e.g.: liberal) tradition(s) and one or more non-Western (e.g. Confucianist, traditional African) tradition or traditions. In that case, mutual understanding of what is implied in any of these traditions, will be a necessary condition for dialogues, but will not be sufficient to overcome the differences. At this point argumentation between all the different traditions - polylogues - ought to start in order to gain more universality in their common attempts. Of course, philosophers doing so will have to presuppose some basic (mainly logical) principles. However, they also will be open to revise other presuppositions relevant to the subject (as, e.g., that persons be individual human beings, and the like).

4.

At this point one has to formulate two more questions: Does philosophy intrisically need such intercultural polylogues? Moreover: Are they possible?

a) I want to answer to the first of these questions with a hypothesis, which I cannot discuss here in any detail. The hypothesis is: Philosophy as suchbe it Occidental, Indian, Chinese, African or from any other cultural background - is confronted to a dilemma, the dilemma of culturality. By this I mean something very simple: Philosophy as such aims at universally acceptable, universally intelligible insights, propositions, and theories. This is one side of the dilemma. The other side:

No philosopher and no philosophical tradition have any means to show and to express what they think other than symbolic systems developed within particular cultures and worldviews. Most philosophical thought is 
expressed in a language - not to forget: in one of many human languages which differ, among other things, in their abilitiy to formulate abstract ideas - and there is no such thing as one language of reason.

Every single language used to express philosophical thought can transport hidden presuppositions that may make plausible something which would be highly implausible or even impossible to formulate in some other language(s). Every language or symbolic system in general has certain particularities which might be a virtue or a vice with respect to philosophy and it is not only language that needs to be mentioned here: religious or weltanschauungs-backgrounds play a role as well.

This dilemma of culturality is the main reason which makes me think that there is an intrinsic need for intercultural polylogues in philosophy. Without such intercultural verification one simply cannot be certain about one's particularities. Therefore, the alternatives to intercultural polylogues in philosophy are only two forms of cultural centrism: either separative centrism (avoiding the claim to universality, aiming only at something which is "true" or "valid" for "us", i.e. for a particular human community) - or expansive/integrative centrism (claiming universality of one's own position and not taking into any account others' positions, as far as these differ from the own position). The outcome will be relativism in the first, mere propaganda and persuasion in the second case. b) Now let us consider the next question, already mentioned before: Are intercultural polylogues in philosophy possible at all?

In controversial matters, stemming from different traditions, we do not know whether one or other or none of the parties is right in the sense that a postulate were universally intelligible or valid, before a dialogue or polylogue has taken place.

A theoretically pure model of polylogue would imply that every party is completely ready to give up its own convictions - except for very few basic principles of logic without which no argumentation would be possible at all - if and only if there are stronger arguments given for the other's position. It is not likely that such a disposition is normally to be expected in real life - not even among philosophers, even less among people strongly bound to religious, political, or deep-rooted cultural thinking habits. 
The first consequence of this observation with respect to intercultural polylogues in philosophy will be that no such thing can be expected from encounters of representatives of any provenience. It is not trivial to underline that philosophical dialogues and polylogues are not between cultures, nor between political units, nor between religions (which would ask for representatives of religions, of states, or of culturally defined communities, all of them relying on or bound to defend some extra-theoretical interest), but between human beings trying to argument for or against propositions or theories on purely theoretical grounds.

Still, this remains a theoretical consideration in itself. It is quite unlikely that discussions between philosophers, whose thought is rooted in culturally different philosophical traditions, ever take place under conditions of complete equality in any non-theoretical matter.

Therefore, we could ask for practically feasible consequences. There might be practices in academic philosophy tending towards intercultural polylogues, as it could be taken as a practical rule to look for the discussion of an issue under consideration in at least one culturally rooted philosophical tradition different from one's own. For Westerners that would mean not to close their lists of authorities at the borders of the occidental lore.

Such opening and curiosity quite often will provide unexpected thoughts and insights - and it is possible thanks to translations and the global nets of intercommunication of our globalizing world.

\section{5.}

We should ask the last question now: What can be expected from intercultural philosophical polylogues?

These are two questions: What can the rest of humankind expect when philosophers activate intercultural dialogues and/or polylogues in their disciplines? And second: What can be expected for philosophy itself from such dialogues and polylogues?

The answer to the first version of the question is not very easy. We certainly ought to distinguish between consequences for other scientific disciplines, and such consequences as might be relevant to non-scientific fields. 
Since academic philosophy would "globalise" in such a perspective at least in the way that it would become natural for philosophers to know the basics of more than their own regional tradition. This, after the impact of colonialism, might not be easy for non-Westerners, just as it will be a difficult task for Westerners, although in a different way. However, parallel interest within other disciplines - as, e.g., in linguistics, psychology, history, social theory and others - might not only help, but bring about interesting questions and viewpoints for a globalizing society, as we would learn about the different concepts of other regional traditions.

Sometimes, such research might have its impact again in philosophical discussions. Here I just want to hint at the fact that ethic questions concerning genetics are usually treated by referring to purely monocultural concepts, which obviously is inadequate.

Furthermore, dialogical and polylogical habits in the field of philosophy could even have an impact on fields other than the scientific one. Such habits and practices could contribute to avoiding common presuppositions of superiority-inferiority of "cultures", "ways of life" etc., even in politics. It is my personal experience that in political discussions about the goals and the means of what formerly has been called "developmental policy", and now is labelled "developmental co-operation" the concrete ways justifying the "co-" often are very unclear and searched for elsewhere. If philosophers were trained in truly inter-cultural encounters in their own field, I do not doubt that they would be asked by others about their respective experiences.

The answer to the second version of the question above can be very short:

By intercultural dialogues and polylogues philosophers may come closer to what they aim to by profession, i.e. to universality. 